\title{
HUMANITARIAN LOGISTICS IN THE DISASTER RELIEF SUPPLY CHAIN: STATE OF THE ART
}

\author{
HAJAR RAILLANI ${ }^{1,2,3}$, LAMIA HAMMADI ${ }^{1}$, MÁRCIA M. ALTIMARI SAMED ${ }^{2}$, \\ ABDESSAMAD EL BALLOUTI ${ }^{1} \&$ VLAD STEFAN BARBU $^{3}$ \\ ${ }^{1}$ Laboratory of Engineering Sciences for Energy, National School of Applied Sciences, UCD, Morocco \\ ${ }^{2}$ Laboratory of Logistics Applied to Urban and Business System, National University of Maringà, Brazil \\ ${ }^{3}$ Laboratory of Mathematics Raphaël Salem UMR 60, University of Rouen - Normandy, France
}

\begin{abstract}
The goal of this work is to undertake a review of the literature on humanitarian logistics and disaster relief supply chain, to highlight the progress of research and to afford direction for the authors' future work. To achieve this goal, different books and articles on humanitarian logistics, relief supply chain and disaster management were consulted, to finally come up with a literature framework that provides firstly the different definitions of humanitarian logistics and its activities, then, move on to the concept of the relief supply chain and its stages, underlining its difference with the commercial supply chain, then continue with the concept of disaster and its different classifications. This is in order to prepare a disaster map which will encompass both natural and manmade disasters. Furthermore, the process of disaster management, activities and measures taken in disaster situations were analysed and explained. Finally, this paper proposes a framework for managing risks in a relief supply chain context. Such a framework aims at not only determining the key critical disaster, using criticality as a risk indicator, but also at providing a tool for decision making before, during and after a disaster.
\end{abstract}

Keywords: humanitarian logistics, humanitarian operations, disaster-relief supply chain, disaster management cycle, risk management.

\section{INTRODUCTION}

Based on data of the Centre for Research on the Epidemiology of Disaster [1], the world is affected by various disasters across the continents, since January 2020. Coronavirus affected $6,180,861$ persons and about 371,299 people died; in the Australian continent, 24 people were killed by fires and about 480 million animals have died; in 2019, 8,500 people were killed due to natural disasters and about 98 million people were affected. Taking into account the increasing number of populations, and the impact of climate change, the impact of disasters will aggravate in the coming decades. Between 2017 and 2018, 335 natural disasters affected over 95.6 million people, killing an additional 9,697 and costing a total of US \$335 billion. In the period 2015 to 2016, the world has registered 376 natural triggered disasters. After 330 disaster registered since the beginning of the century in 2014, this increase could be a sign of an inversion in the trend to the decline in the annual number of disasters since 2005, even if the 2015 number remains below its average annual for the period from 2005 to 2014 (EM-DAT [1]).

"Disasters come to test the reactivity of our systems, especially the capacity of different actors to work together. They demand solutions that include governments, military, civil society and humanitarian organizations" [2]. When a disaster (natural or manmade) occurs, an efficient disaster relief supply chain plays a critical role in quickly distributing relief supplies to the affected area for rapid recovery. In this context, several academic research studies were conducted to investigate different aspects of disaster relief supply chain management. Lodree and Taskin [3] proposed an insurance risk management framework for decision-makers to quantify the risks and benefits associated with stocking decisions for disaster relief efforts or supply chain disruption. Maon et al. [4] proposed a theoretical model 
for developing a supply chain in disaster relief operations through cross-sector socially oriented collaboration. Falasca et al. [5] developed a decision support framework for assessing supply chain resilience to disasters.

Based on the above, the aim of this article is to make a review of literature on humanitarian logistics, disaster relief supply chain and disaster management process. It proposes a new framework for managing risks in a disaster relief supply chain context.

This paper is structured as follows. Section 2 introduces the concept of humanitarian logistics from five-tiered prospects: disaster definition, disaster classification, definition of humanitarian logistics, disaster relief supply chain, and relief supply chain operations. Section 3 introduces the disaster management process in a relief supply chain context. Section 4 presents a new framework for managing risks in disaster situations. Finally, Section 5 concludes the paper.

\section{HUMANITARIAN LOGISTICS CONTEXT}

This section presents the definitions about disasters and humanitarian logistics according to several authors and gives a classification of disasters in terms of categorization, generic group and specific group, it also introduces the concept of disaster relief supply chain as a response to the different types of disaster.

\subsection{Disaster definition}

"A disaster can be defined as a shocking event that seriously disrupts the functioning of a community or society, by causing human, material, economic or environmental damage that cannot be handled by local agencies through standard procedures" [6]. The United Nations Office for Disaster Risk Reduction (UNISDR) [7], described the disaster as "a serious disruption of the functioning of a society, causing widespread human, material, or environmental losses which exceed the ability of affected society to cope using only its own resources" [7]. Alexander [8] and UNISDR [7], introduced the concepts of "hazard" and "vulnerability" into the definition of disaster, and defined it as "a result of a combination of hazards, vulnerability and lack of measures. Using special measures for planning, coordinating and utilizing appropriate resources will minimize the adverse impact of disasters". Iyer and Mastorakis [9], Biswas and Choudhuri [10] considered disaster as "a dynamic mechanism that begins with the activation of a hazard and flows through the system as a series of events, in a logical sequence to produce a loss to life, property and livelihood by negatively influencing the emergency systems".

So, it can be said that a disaster is an unexpected event that disrupts the normal functioning of the system, due to natural or technological causes, and leads to human, economic, material and environmental losses. It requires the intervention of the various actors of the community in order to regain initial balance.

\subsection{Disaster classification}

Disasters can be caused by natural or human events. In addition, many different classification criteria can be found in the literature. Taking this into account, disasters are here grouped into the following different categories: natural or manmade disasters, slow or sudden onset disasters, localized and slow onset disasters, dispersed and slow onset disasters, localized and sudden onset disasters or dispersed and sudden onset disasters.

In Table 1, a summary of classification of disasters is presented in terms of categorization criteria and generic group, according to several authors. 
Table 1: Framework of disaster classification.

\begin{tabular}{|c|c|c|c|c|c|c|c|}
\hline \multirow[b]{2}{*}{ Authors } & \multicolumn{6}{|c|}{ Classification criteria } & \multirow[t]{2}{*}{ Group } \\
\hline & Frequency & Severity & Source & $\begin{array}{c}\text { Speed } \\
\text { of onset }\end{array}$ & Time & Location & \\
\hline $\begin{array}{l}\text { van } \\
\text { Wassenhove } \\
{[12]}\end{array}$ & & & $\mathrm{X}$ & & & & $\begin{array}{l}\text { 1.Natural disaster } \\
\text { 2.Technological } \\
\text { disaster }\end{array}$ \\
\hline $\begin{array}{l}\text { www.unit.eu/ } \\
\text { [13] }\end{array}$ & $\mathrm{X}$ & $\mathrm{X}$ & & & & & $\begin{array}{l}\text { 1.Major natural } \\
\text { risk } \\
\text { 2.Major } \\
\text { technological } \\
\text { risk }\end{array}$ \\
\hline Apta [14] & & & & $\mathrm{X}$ & & & $\begin{array}{l}\text { 1.Slow } \\
\text { 2.Sudden }\end{array}$ \\
\hline $\begin{array}{l}\text { Tomasini and } \\
\text { van } \\
\text { Wassenhove } \\
{[2]}\end{array}$ & & & $\mathrm{X}$ & & & & $\begin{array}{l}\text { 1.Natural } \\
\text { 2.Technological }\end{array}$ \\
\hline Apta [14] & & & & & $\mathrm{X}$ & $\mathrm{X}$ & $\begin{array}{l}\text { 1. Localized and } \\
\text { Slow onset } \\
\text { 2.Dispersed and } \\
\text { Slow onset } \\
\text { 3.Localized and } \\
\text { Sudden onset } \\
\text { 4.Dispersed and } \\
\text { Sudden onset } \\
\end{array}$ \\
\hline $\begin{array}{l}\text { Zanjirani } \\
\text { Farahani et al. } \\
\text { [15] }\end{array}$ & & & $\mathrm{X}$ & & & & $\begin{array}{l}\text { 1.Natural } \\
\text { 2.Technological }\end{array}$ \\
\hline $\begin{array}{l}\text { www.emdat.be } \\
\text { [1] }\end{array}$ & & & $\mathrm{X}$ & & & & $\begin{array}{l}\text { 1.Natural } \\
\text { 2.Technological }\end{array}$ \\
\hline $\begin{array}{l}\text { Adiguzel } \\
{[11]}\end{array}$ & & & $\mathrm{X}$ & & & & $\begin{array}{l}\text { 1. Nature related } \\
\text { events } \\
\text { 2.Manmade }\end{array}$ \\
\hline
\end{tabular}

As can be seen in the table, each author has classified disasters according to different criteria and has adopted their own classification. In this paper, a classification according to the nature of the disaster will be adopted: natural or manmade.

\subsection{Definition of humanitarian logistics}

"Disaster logistics, also known as humanitarian aid logistics, is designed to cover the needs of damaged and vulnerable individuals and to alleviate their suffering" [11]. According to the International Federation of Red Cross and Red Crescent Societies in 2015 [16]: "Humanitarian logistics consists of processes and systems involved in mobilizing people, resources and knowledge to help vulnerable communities affected by natural disasters or complex emergencies. It seeks a prompt response, aiming to serve the largest number of people, avoid shortages and waste, organize various donations and, above all, operate within a limited budget". 
According to Apta [14] "humanitarian logistics is a critical element of an effective disaster relief process and is described as a special branch of logistics with challenges such as demands surge, uncertain supplies, critical time window in face of infrastructure vulnerabilities and vast scope and size of the operations". So humanitarian logistics is defined as "the process of planning, implementing and controlling the efficient, cost-effective flow and storage of goods and materials as well as related information from the point of origin to the point of consumption for the purpose of alleviating preparedness, planning, procurement, transport, warehousing, tracking and tracing, customs and clearance" [17]. Kovács and Spens [18], described humanitarian logistics as "a function that encompasses very different operations at different times, and as a response to various catastrophes. All these operations have the common aim to aid people in their survival. Nonetheless, aid to assist the development of a region, famine aid and the running of refugee camps is substantially different from the kind of aid needed after a natural disaster".

According to Daud [19] "humanitarian logistics encompasses the process of mobilizing people, resources, skills and knowledge to help the disaster's victim. In the humanitarian process, logistics is the central of all the mobilization activity as it served as the bridge between the disaster preparedness and response, procurement and distribution and headquarters and the field. It also can be one of the most expensive parts in the relief operation and the effectiveness of the operation is always being monitored in order to improve the operation and to minimize the operating cost with the maximum of result's operation" [19].

Finally, evidence can be found that humanitarian logistics refers to the activities which manage the logistical flows, in case of disasters. It is to save lives and make available the resources corresponding to the needs determined by respecting the type and impact degree of the disaster, the service expected, safety and security conditions deemed satisfactory.

\subsection{Disaster relief supply chain}

According to Wood et al. [20] "relief itself can be defined as a foreign intervention into society to help local citizens". The purpose of disaster relief operations is to "design the transportation of first aid material, food, equipment, and rescue personnel from supply points to a large number of destination nodes geographically scattered over the disaster region and the evacuation and transfer of people affected by the disaster to the health care centers safely and very rapidly" [21]. Barbarosoğlu et al. [21], described the relief supply chain as that designing "the transportation of first aid material, food, equipment, and rescue personnel from supply points to a large number of destination nodes geographically scattered over the disaster region and the evacuation and transfer of people affected by the disaster to the health care centers safely and very rapidly" [21].

The humanitarian supply chain starts from suppliers and donors to the recipients or people is need, differently from the commercial one where there is just two types of operations: supplying and distribution; the financial flow in the humanitarian supply chain is intended to suppliers and recipients and come from donors and organizations, the goods flow come from suppliers to the distribution units to finally recipients as can be seen in Fig. 1.

\subsection{Relief supply chain operations}

Tomasini and van Wassenhove [2] define 5 flows that must be managed in the humanitarian supply chain, which they called 5B's: boxes, bytes, bucks, bodies and business. For these 


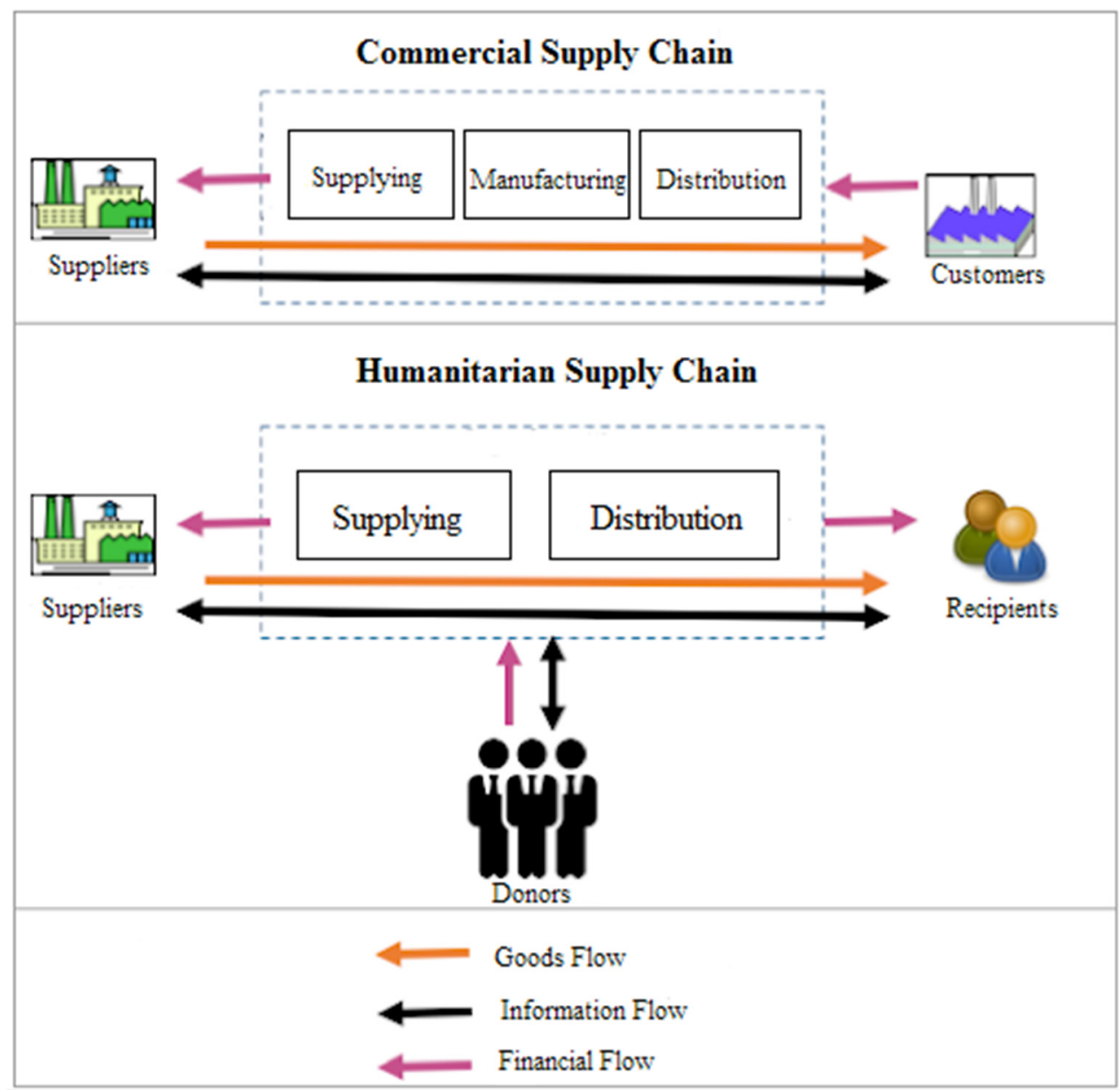

Figure 1: Humanitarian supply chain design vs commercial supply chain [22].

authors, the difficulties inherent in the management of the supply chain in humanitarian logistics can be summarized, as follows:

- Difficulty in carrying out its operations with limited resources;

- Difficulty in reconciling ambiguous objectives;

- Difficulty in making decisions due to the high degree of uncertainty;

- Difficulty in carrying out actions in a politicized environment;

- Difficulty in dealing with urgent problems.

To promote success in response actions it is necessary to include a link between preparedness and response strategies. This element is called Triple-A Supply Chain, where A's correspond to agility, adaptability and alignment.

The disaster relief supply chain is composed of three main operations: supply acquisition and procurement, pre-positioning and warehousing and transportation [3]. 
The first step is related to all activities of procurement of the relief items [23], which come from suppliers or donors. "Goods are taking from suppliers by applying various procurement techniques (direct purchasing, e-procurement, tenders, ...). The main challenges are here the reduction of purchasing costs (considering price inflation in local markets after disasters) and lead times by still ensuring availability and the coordination of in-kind donations" [23]. "Most procurement decisions are short-termed, as demand can only be evaluated after a need's assessment performed in the area affected. Therefore, relief organizations stockpile ready-to-dispatch inventory in locations with access to disaster-prone regions" [24]. "Transportation is the next stage in the supply chain and it includes the movement of personnel, equipment and necessary items. First, the goods are brought to central distribution centers, distribution intermediary points or local distribution centers and finally transported to the regions affected by the disaster", as shown in Fig. 2 [15].

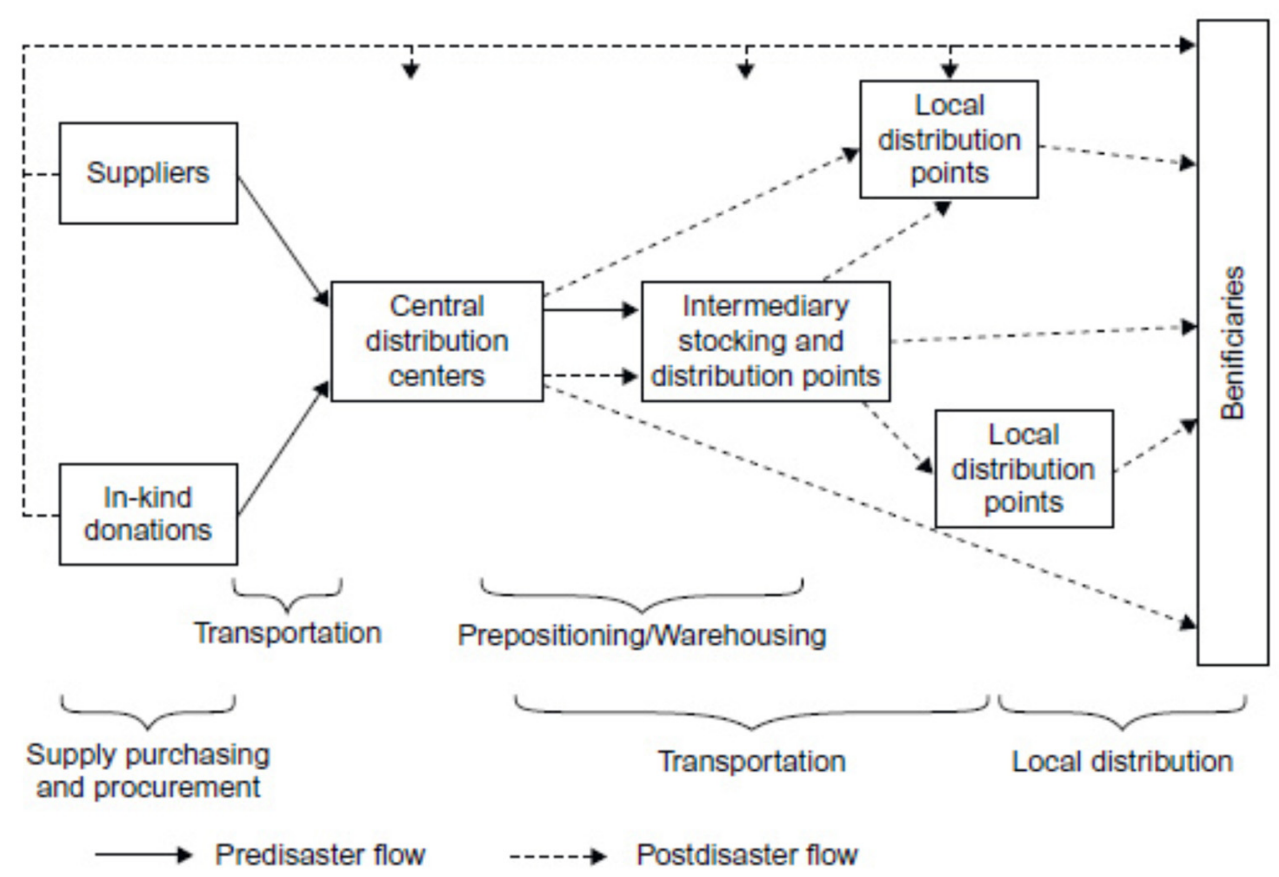

Figure 2: Humanitarian logistics chain structure [15].

As can be seen, the disaster relief supply chain structure differs following the disaster type and actors engaged, but they all have common flows, actors and blocks, composed of procurement, inventory and transportation management.

\section{DISASTER MANAGEMENT}

This section introduces a theoretical framework of disaster management process. We used literature to define basic terms in the purpose of making an elementary understanding. 


\subsection{Disaster management}

According to Zanjirani Farahani et al. [15] "disaster management is a set of processes designed to be implemented before, during and after disasters to prevent or mitigate their effects". It "aims at reducing or avoiding potential losses from hazards, assuring prompt and appropriate assistance to victims of disaster, and achieving rapid and effective recovery" [25]. "Disaster Risk Management includes sum total of all operations, programs and measures which can be taken up before, during and after a disaster with the aim to avoid a disaster, reduce its impact or recover from its losses" [26]. It "focuses on the organization and management of resources and responsibilities to address all aspects of emergencies and disasters, including preparedness, response and initial recovery steps" [27].

\subsection{Disaster management cycle}

"The disaster management cycle refers to the process by which governments, businesses, and civil society plan for and reduce the impact of disasters, react during and immediately following a disaster and take steps to recover after a disaster has occurred. The four disaster management phases illustrated here do not always, or even generally, occur in isolation or in this precise order. Often phases of the cycle overlap and the length of each phase greatly depends on the severity of the disaster" [26].

According to Tomasini and van Wassenhove [2], the full cycle of disaster management includes four steps:

- Mitigation: addresses the proactive social component of emergencies. This includes laws and mechanisms that reduce the vulnerability of the population and increase their resilience.

- Preparedness: in this step, the actors involved in the disaster relief supply chain should take measures and response mechanisms to detect factors that society has not been able to mitigate (withstanding risks and vulnerability).

- Response: is the act of attending to the disaster.

- Rehabilitation/Recovery: it is the last step of the disaster management cycle, when society supported by surviving institutions and infrastructure try to reduce losses and return some form of normality to the victims' lives.

Kovács and Spens [28] summarize the phases of disaster relief operations as shown in Fig. 3.

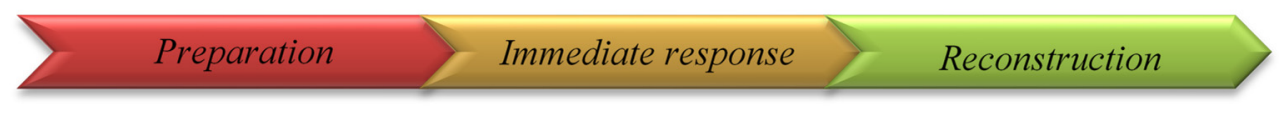

Figure 3: Relief supply chain operations [28].

\subsubsection{Preparation}

Basically, it means "putting in place the response mechanisms to counter factors that society has not been able to mitigate (withstanding risks and vulnerability)" [2]. Preparedness measures differ depending on the type of disaster, they can be, e.g. a free training, evacuation plans developed and prepared in advance, Also, measures can be taken to reduce the disaster losses. 


\subsubsection{Immediate disaster response}

"Once a disaster occurs, the emergency plans of regional actors come into action. But independently of how well, however, prepared these actors are, they will need to operate in an environment with a destabilized infrastructure" [28]. "The nature of most disasters needs an immediate response, hence supply chains demand to be designed and deployed at once even though the knowledge of the situation is very limited" [17], [20], [28]. "It is often unknown which resources are available, and even the involvement and contribution of suppliers is unpredictable" [28]. "This leads to many redundancies and duplicated efforts and materials" [28]. "In the immediate response phase, remote aid agencies assume the needs of disaster victims based on very limited information" [20]. "Assumptions need to be made regarding the kind and quality of supplies needed, the times and locations of demand, as well as the nature of the potential distribution of these supplies to any point of demand" [20], [28].

\subsubsection{Reconstruction}

The last phase is reconstruction, "when actors involved look for restoring some form of normality to the victims' lives" [3], and "the regional actors can begin to help victims in the location of their family and friends" [27]. As discussed before, the recovery phase is important as disasters can have long-term effects on a region. In addition, disasters can also have long-term effects on the management of companies.

Finally, according to the United Nations, 2015 [27] "disaster-risk management is the systematic process of using administrative directives, organizations, and operational skills/capacities to implement strategies, policies and improved coping capacities. This is in order to lessen the adverse impacts of hazards, and the possibility of disaster. When successful, disaster-risk management efforts aim at reducing the effects of hazards, through activities and measures related to prevention, mitigation, and preparedness" [27].

\section{PROPOSED FRAMEWORK OF DISASTER RISK MANAGEMENT}

"Risk management has been known as an important management discipline in a number of fields and sectors. Works in such fields have helped to develop the basic theories of risk management, such as the nature of risk, risk measurement, the concept of acceptable risk and the principles of likelihood and consequence" [29].

Disaster management is a cyclical process. The end of one phase constitutes the beginning of another, even if a phase of the cycle must not necessarily end to make room for another. Often, several phases take place simultaneously.

The authors' objective behind this framework is to merge risk management with the disaster management cycle in order to exploit the risk management tools in a disaster situation.

The framework shown in Fig. 4, presents the interactive architecture of risk management deployed in disaster situations to support decision making during each phase of the disaster management cycle. This is because, taking a decision at the right time during each phase leads to a better preparation, better alerts, reduced vulnerability and/or prevention of future disasters.

The cycle in blue shown in Fig. 4 represents the risk management process while the orange dotted arrows represent the correspondence between the stages of risk management and those of the disaster management cycle.

Our process of risk management in a disaster context contains six basic steps. 

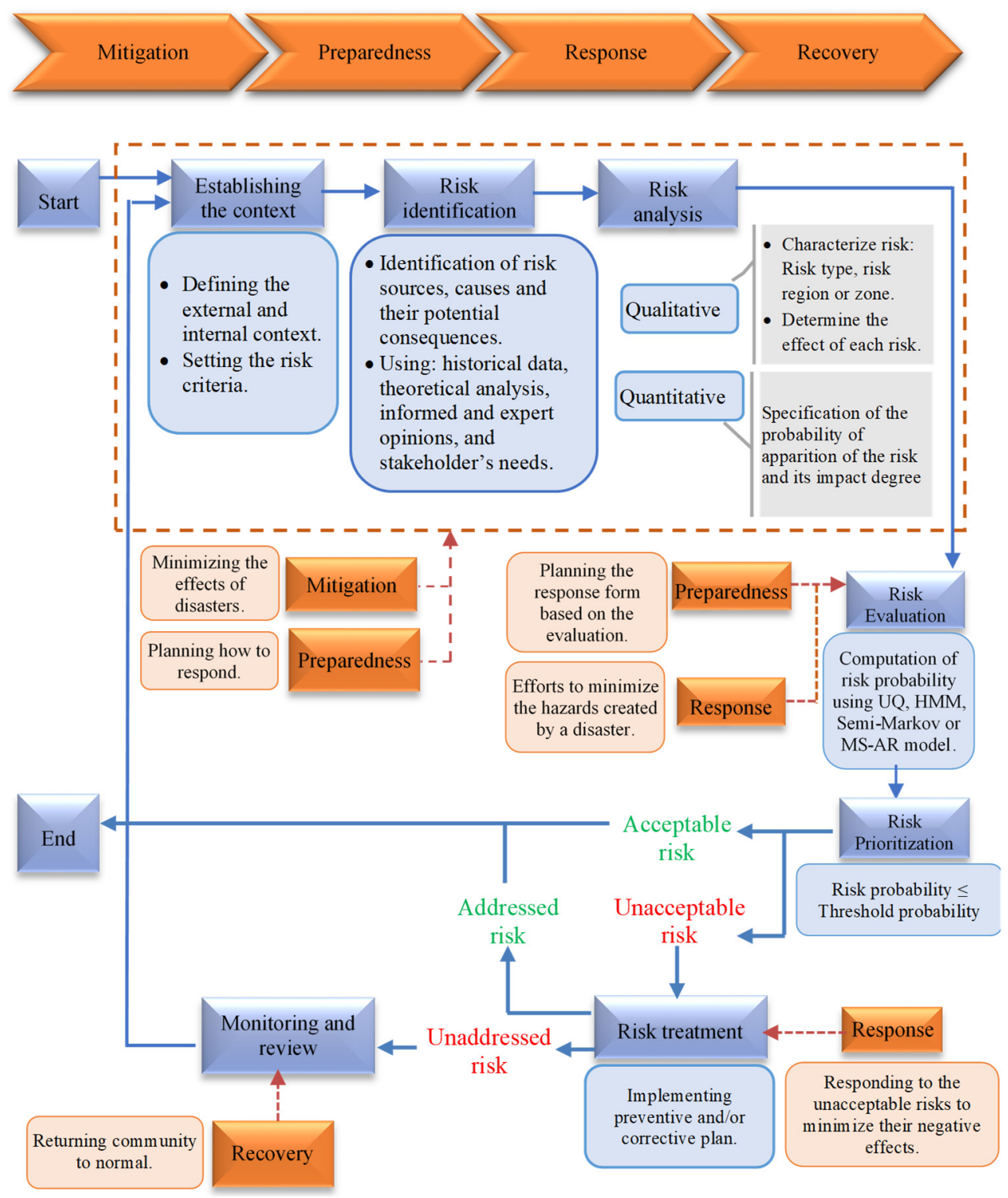

Figure 4: Disaster and risk management framework.

\subsection{Establishing the context}

Any process of risk management begins by establishing the context of what needs to be managed. At this stage we define the internal and external context, the objectives and the risk criteria. Determining the context helps set the parameters for the next steps of risk management process. 


\subsection{Risk identification}

Risk identification allows decision-makers to be aware of events likely to create uncertainty [25]. It is a demanding step that requires an effort to analyse and imagine the sources of risk [30]. Hillson [31] classifies methods dedicated to identifying risks into three categories: creative methods, experience-based methods and group or individual methods. Creative methods have led to reflection on the identification of risks, such as the Delphi method. Experience-based methods use the knowledge from the analysis of risk situations encountered in the past and people's experience. In this regard, Hillson [31] presented the Nominal Group Technique Method (NGT) which begins with individual brainstorming, then it goes on to sharing and assessing the risks identified. Risk identification methods also depend on the area of application, for example the HAZID methods "HAZard IDentification" and HAZOP "HAZard and OPerability" reserved for the process industry [30].

\subsection{Risk analysis and evaluation}

The assessment stage consists of measuring the level of risk associated with the events generated by the identification step [29]. This step is of great importance because it determines a ranking of risks according to their importance and, consequently, it influences the prioritization of the actors to be undertaken to treat them. The complexity of this step is manifested in a large number of risks to be assessed and the accuracy of estimates made. To overcome this problem, the AS/NZS standard [30] recommends the elimination of minor risks whose aim is to reduce the number of risks to be taken into account. In addition, it advocates an evaluation based on an iterative process to readjust initial assessments and minimize bias resulting from overestimation or underestimation of events. There are two main approaches for risk assessment: the qualitative approach and the quantitative approach.

\subsubsection{Qualitative approach}

The qualitative approach has been proposed for cases where the numerical quantification of the risk cannot be completed due to the lack of information or the complexity of this task.

In support, the problem of estimating the intangible consequences generated by the degradation of a company's reputation is cited [30]. Qualitative assessment depends on several parameters; probability of occurrence and gravity. The final result of the qualitative risk assessment is presented by an expression such as "the risk is intolerable" or "the risk is acceptable".

\subsubsection{Quantitative approach}

Quantitative techniques consider the risk as an estimable quantity by mathematical relations by exploiting real data. The literature distinguishes between direct quantitative evaluation and indirect quantitative evaluation. The first is based on the observation of the case studied to estimate the level of risk using an extreme law of values. The second is based on a probabilistic model of occurrence and evolution of the risk process [30]. The conventional formula used for the quantitative risk assessment is based on the specification of the probability of apparition of the risk and the degree of its impact [30]. The following formula expresses this relationship: Risk $=$ Occurrence probability $*$ Gravity.

The steps of establishing the context, risk identification and risk analysis in the risk management process correspond to the phases of mitigation and preparedness in the disaster management cycle which is shown with the orange dotted arrows. 


\subsection{Risk prioritization}

The purpose of risk prioritization is to assist in making decisions, based on the outcomes of risk analysis and evaluation, about which risks need treatment and the priority for treatment implementation. It involves comparing the risk probability with the threshold probability. Based on this comparison, the need for treatment can be considered.

\subsection{Risk treatment}

Risk treatment allows one to eliminates the risk or reduces it to an acceptable level. Mees [32] defined four strategies for the risk treatment: Eliminate the risk by changing the way of carrying out an activity in order to prevent the triggering of an adverse event. Reduce the risk by implementing countermeasures likely to minimize the probability of occurrence of a risk or of mitigating its consequences. Transfer the risk by a contract, to a third party who accepts to manage it. This allows the organization to have more guarantees, ex. the insurance. Accept the risk which is the retention strategy adopted by an organization when the impact of the occurrence of an adverse event is considered to be low. However, there are cases where taking on the risk is not a choice, in particular in the case where the risk treatment cost is very high.

The risk treatment can be matched with the response step in the disaster management cycle, where preventive and/or corrective plan to minimize the negative effects of the risk or the disaster are implemented.

\subsection{Monitoring and review}

"Risks are not static circumstances but they change over time. As a consequence, a risk that has previously been considered as acceptable may for any number of reasons be regarded subsequently as an unacceptable risk and need some form of treatment strategy. The monitoring and review phases are crucial to test the current effectiveness of controls to ensure that the risk management process achieves its intended goal. This will help to determine whether the controls are sufficient to address the identified risks or whether they need to be strengthened or supplemented in some way. Alternatively, existing controls may be found to be excessive, thereby consuming resources that may be better allocated to an alternative source of risk" [29].

The phase of monitoring and reviewing corresponds to the rehabilitation and recovery step in the disaster management cycle where we try to return the community to normal and implement preventive plans to deal with future disasters.

\section{CONCLUSION AND FUTURE WORKS}

This paper reviews the concept of humanitarian logistics and disaster relief supply chain. We have first examined the existing humanitarian logistics literature within the fields of disaster relief supply chain and disaster management. We identified both the phases of the disaster cycle and risk management after going through a detailed classification of disasters. Following a discussion of humanitarian context and disaster management, the elements of the framework were identified and the supporting literature was discussed. Following this review, we identified two directions for our future research in the field of disaster relief supply chain. The first one is to use uncertainty quantification and stochastic modelling in order to better analyse the disaster behaviour and to predict the areas that are most sensitive and vulnerable to risks. The second one is to develop algorithms to determine the optimal location of a relief station in the context of the Moroccan disaster supply chain. 


\section{REFERENCES}

[1] Centre for Research on the Epidemiology of Disasters-CRED, EM-DAT: The international disaster database. https://public.emdat.be/data. Accessed on: 10 Feb. 2020.

[2] Tomasini, R.M. \& van Wassenhove, L.N., Humanitarian Logistics, Houndmills: Basingstoke and Palgrave Macmillan: New York, NY, p. 193, 2009.

[3] Lodree Jr., E.J. \& Taskin, S., An insurance risk management framework for disaster relief and supply chain disruption inventory planning. Journal of the Operational Research Society, 59(5), pp. 674-684, 2008. DOI: 10.1057/palgrave.jors.2602377.

[4] Maon, F., Lindgreen, A. \& Vanhamme, J., Developing supply chains in disaster relief operations through cross-sector socially oriented collaborations: A theoretical model. Supply Chain Management, 14(2), pp. 149-164, 2009.

DOI: $10.1108 / 13598540910942019$.

[5] Falasca, M. et al., A decision support framework to assess supply chain resilience. Proceedings of the 5th International ISCRAM Conference, Washington, DC, pp. 596605, 2008.

[6] Jiang, Y. \& Yuan, Y., Emergency logistics in a large-scale disaster context: Achievements and challenges. International Journal of Environmental Research and Public Health, 16(5), p. 779, 2019. DOI: 10.3390/ijerph16050779.

[7] ReliefWeb, UNISDR terminology on disaster risk reduction: World. https://reliefweb.int/report/world/2009-unisdr-terminology-disaster-risk-reduction. Accessed on: 21 Feb. 2020.

[8] Alexander, D., Towards the development of standards in emergency management training and education. Disaster Prevention and Management, 12(2), pp. 113-123, 2003. DOI: $10.1108 / 09653560310474223$.

[9] Iyer, G.V. \& Mastorakis, N.E., Important elements of disaster management and mitigation and design and development of a software tool. Proceedings of the 7th WSEAS International Conference on Mathematics and Computers in Business and Economics, Cavtat, Croatia, 13-15 Jun., pp. 102-121, 2006.

[10] Biswas, B.C. \& Choudhuri, S.K., Digital information resources for disaster management of libraries and information centres. Bangladesh Journal of Library Information Science, pp. 12-21, 2012.

[11] Adiguzel, S., Logistics management in disaster. Pressacademia, 6(4), pp. 212-224, 2019. DOI: 10.17261/Pressacademia.2019.1173.

[12] van Wassenhove, L.N., Humanitarian aid logistics: Supply chain management in high gear. Journal of the Operational Research Society, 57(5), pp. 475-489, 2006.

DOI: $10.1057 /$ palgrave.jors.2602125.

[13] Classification des risques: Les types de risque. www.unit.eu/cours/cyberrisques/ etage_2/co/Module_Etage_2_7.html. Accessed on: 10 Feb. 2020.

[14] Apta, A., Humanitarian logistics: A new field of research and action. Foundations and Trends ${ }^{\circledR}$ in Technology, Information and Operations Management, 3(1), pp. 1-100, 2009. DOI: 10.1561/0200000014.

[15] Zanjirani Farahani, R., Rezapour, S. \& Kardar, L., Logistics Operations and Management Concepts and Models, Elsevier: London, pp. 291-326, 2011.

[16] International Federation of Red Cross and Red Crescent Societies, IFRC Annual Report, 2015. https://media.ifrc.org/ifrc/who-we-are/performance-and-accountability/ ifrc-annual-report-2015/. Accessed on: 10 Mar. 2020.

[17] Beamon, B.M. \& Balcik, B., Distribution network design for humanitarian relief chains, IE Graduate Seminar, 8 Nov., p. 39, 2005. 
[18] Kovács, G. \& Spens, K.M., Knowledge sharing in relief supply chains. International Journal of Networking and Virtual Organisations, 7(2/3), p. 222, 2010.

DOI: 10.1504/IJNVO.2010.031219.

[19] Daud, M.S.M., Humanitarian logistics and its challenges: The literature review. International Journal of Supply Chain Management, 5(3), p. 5, 2016.

[20] Wood, D.F., Barne, A., Murphy, P. \& Wardlow, D.L., Logistics of famine relief. International Logistics, Springer: Boston, MA, pp. 325-338, 1995.

[21] Barbarosoğlu, G., Özdamar, L. \& Çevik, A., An interactive approach for hierarchical analysis of helicopter logistics in disaster relief operations. European Journal of Operational Research, 140(1), pp. 118-133, 2002.

DOI: 10.1016/S0377-2217(01)00222-3.

[22] Portail Logistique, Transport et Supply Chain, La logistique, définition et enjeux. www.faq-logistique.com/Logistique.htm. Accessed on: 25 Feb. 2020.

[23] Balcik, B., Beamon, B.M., Krejci, C.C., Muramatsu, K.M. \& Ramirez, M., Coordination in humanitarian relief chains: Practices, challenges and opportunities. International Journal of Production Economics, 126(1), pp. 22-34, 2010.

DOI: 10.1016/j.ijpe.2009.09.008.

[24] Balcik, B. \& Beamon, B.M., Facility location in humanitarian relief. International Journal of Logistics Research and Applications, 11(2), pp. 101-121, 2008.

DOI: 10.1080/13675560701561789.

[25] Hallikas, J., Karvonen, I., Pulkkinen, U., Virolainen, V.-M. \& Tuominen, M., Risk management processes in supplier networks. International Journal of Production Economics, 90(1), pp. 47-58, 2004. DOI: 10.1016/j.ijpe.2004.02.007.

[26] Khan, P.H., Disaster management cycle: A theoretical approach. Management and Marketing Journal, 6(1), pp. 43-50, 2008.

[27] UN-SPIDER Knowledge Portal, Risks and disasters. www.un-spider.org/risks-anddisasters. Accessed on: 10 Mar. 2020.

[28] Kovács, G. \& Spens, K.M., Humanitarian logistics in disaster relief operations. International Journal of Physical Distribution and Logistics Management, 37(2), pp. 99-114, 2007. DOI: 10.1108/09600030710734820.

[29] Hammadi, L. \& Ouahman, A.A., An approach based on FMECA methodology for a decision support tool for managing risk in customs supply chain: A case study. International Journal of Manufacturing Technology and Management, 32(2), p. 22, 2018.

[30] Najib, M., Gestion des risques liés au transport des matières dangereuses. Thesis, p. $200,2014$.

[31] Hillson, D., Extending the risk process to manage opportunities. International Journal of Project Management, 20(3), pp. 235-240, 2002.

DOI: $10.1016 / \mathrm{S} 0263-7863(01) 00074-6$.

[32] Mees, W., Risk management in coalition networks. Third International Symposium on Information Assurance and Security, Manchester, UK, Aug. 2007, pp. 329-336, 2007. DOI: 10.1109/IAS.2007.76. 